\title{
Opioid-Induced Sickle Cell Crisis With Multiple, Life-threatening Complications
}

Ashley Griswold Haggerty, DO; Andrew Koons, DO; Gillian Beauchamp, MD; Matthew D. Cook, DO; Robert D. Cannon, DO; Kenneth D. Katz, MD

From the Department of Pediatrics (Dr Haggerty) and the Department of Emergency and Hospital Medicine, Division of Toxicology (Drs Koons, Beauchamp, Cook, Cannon, and Katz) at the Lehigh Valley Health Network/ University of South Florida Morsani College of Medicine (Lehigh Valley campus) in Bethlehem, Pennsylvania.

The abstract from this article was presented at the American College of Medical Toxicology (ACMT) Annual Scientific Meeting, April 6-8, 2018 in Washington, DC and

the PACEP18 Annual Scientific Assembly, March 20, 2018 in Harrisburg, PA.

Financial Disclosures: None reported.

Support: None reported.

Address correspondence to Kenneth D. Katz, MD, EM Research, 4th Floor,

South Wing, 2545

Schoenersville Road,

Bethlehem, Pennsylvania 18017-7300.

Email:

Kenneth_D.Katz@lvhn.org

Submitted

November 10, 2019; revision received January 28, 2020; accepted February 18, 2020.

The risk of opioid use disorder among patients with sickle cell disease who are treated with chronic opioids remains unclear, but the complications associated with opioid use and overdose can be accentuated in those with sickle cell disease. In this case report, we describe a 13-year-old girl with sickle cell disease who presented to the emergency department after a morphine overdose causing renal infarction, acute kidney injury, acute respiratory distress syndrome, and posterior reversible encephalopathy syndrome.

J Am Osteopath Assoc. 2020;120(11):770-773. Published online October 5, 2020. doi:10.7556/jaoa.2020.125

Keywords: acute respiratory distress, kidney injury, opioids, opioid use disorder, overdose, sickle cell crisis

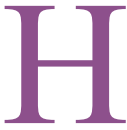
omozygous sickle cell disease is the most common and severe form of sickle cell disease and predisposes patients to a range of complications, including splenic infarction, aplastic crises, and osteomyelitis. ${ }^{1}$ Moreover, hypoxic, acidic, and hyperosmolar environments promote red blood cell sickling and vaso-occlusion, which can cause dactylitis, avascular necrosis, acute chest syndrome, stroke, renal infarction, and priapism. ${ }^{1,2}$

Management for acute sickle cell disease crises includes exchange transfusions, intravenous (IV) fluids, and analgesic administration that often includes the use of opioids. ${ }^{1}$ It is well-known that the increase in opioid prescribing in the 1990s and early $2000 \mathrm{~s}$ sparked an epidemic of opioid use disorder in the United States. Opioids are commonly used to manage pain in patients with sickle cell disease; however, the incidence of opioid use disorder remains unclear and understudied. Given that excessive $\mu$-receptor agonism can worsen hypoxemia associated with sickle cell disease crisis, opioid overdose can cause potentially devastating and life-threatening complications. We present a case of opioid overdose in a pediatric patient with sickle cell disease that resulted in multiple, life-threatening sequelae.

\section{Report of Case}

A 13-year-old girl with sickle cell disease who had been treated with prescribed morphine sulfate (which had been discontinued several months prior due to concerns of misuse) was transported to the emergency department (ED) because her mother found her unresponsive at home with sonorous respirations. The patient's mother informed the emergency medical services providers that the patient had received an infusion in the hematology clinic the day prior and had not been feeling well. On the morning of ED presentation, the patient ingested a $25-\mathrm{mg}$ diphenhydramine tablet and then took a nap 
around 10:00 AM. When the patient's mother could not wake her at approximately 3:00 PM, she called 911. Upon arrival, emergency medical services described agonal respirations and miosis. The patient was endotracheally intubated in the prehospital setting for airway protection and hypoxemia. After intraosseous (IO) access was established, the patient was transported to a pediatric ED.

In the ED, the patient was unresponsive with a Glasgow Coma Scale (GCS) score of 3T (severe). The patient's vital signs included the following: blood pressure, 95/57 mmHg; pulse, 161 beats per minute; temperature, $38.1{ }^{\circ} \mathrm{C}\left(100.5{ }^{\circ} \mathrm{F}\right)$; pulse oximetry, $100 \%$ on $100 \%$ oxygen via bag-valve-mask ventilation of her endotracheal tube. Physical examination was notable for diaphoresis and 1 to $2 \mathrm{~mm}$ sluggish pupils. Due to difficulty with bag-valve ventilation, $0.8 \mathrm{mg}$ naloxone was administered via intraosseous infusion. The patient immediately awoke, promptly self-extubated, and vomited twice while maintaining her airway. Her complete blood count demonstrated a hemoglobin of $10.5 \mathrm{~g} / \mathrm{dL}$ (reference range, 11.1-15.7 g/dL) and a platelet count of 142 thousand $/ \mathrm{mm}^{3}$ (reference range, 140-350 thousand $/ \mathrm{mm}^{3}$ ). Coagulation study results included the following: Pro Time, 25.4 seconds (reference range, 12.0-14.6 seconds); D-dimer, greater than $20.00 \mu \mathrm{g} / \mathrm{mL}$ (reference range, $<0.50 \mu \mathrm{g} / \mathrm{mL}$ ); fibrinogen, $129 \mathrm{mg} / \mathrm{dL}$ (reference range, 180-500 mg/dL). Liver enzyme results included aspartate aminotransferase of $221 \mathrm{U} / \mathrm{L}$ (reference range, $<41 \mathrm{U} / \mathrm{L}$ ) and alanine aminotransferase of $132 \mathrm{U} / \mathrm{L}$ (reference range, $<56 \mathrm{U} /$ L). Serum chemistries included a creatinine result of $1.58 \mathrm{mg} / \mathrm{dL}$ (reference range, $0.57-0.80 \mathrm{mg} / \mathrm{dL}$ ). The patient's serum lactate measured $8.9 \mathrm{mmol} / \mathrm{L}$ (reference range, $0.5-2.1 \mathrm{mmol} / \mathrm{L}$ ). A preliminary urine drug screen of abuse immunoassay detected opiates. Serum acetaminophen, salicylate, and ethanol concentrations measured $2 \mu \mathrm{g} / \mathrm{mL},<2 \mathrm{mg} / \mathrm{dL}$, and undetectable, respectively. A chest radiography revealed hypoinflated lungs with no acute cardiopulmonary process and stable cardiomegaly. A head computed tomography (CT) scan showed no acute intracranial abnormality.
In the ED, the patient became somnolent again, so a subsequent dose of intravenous (IV) naloxone (0.8 $\mathrm{mg}$ ) was administered. She became more arousable, vomited once more, but continued to maintain her airway with a GCS of 11 (moderate). The patient scored 10 (definite) on the Naranjo Adverse Drug Reaction Probability Scale.

The patient was admitted to the pediatric intensive care unit. On hospital days (HD) 1 and 2, she demonstrated intermittent periods of somnolence requiring IV naloxone administration $(0.8 \mathrm{mg})$ with subsequent vomiting. She received IV fluids, albumin, ceftriaxone, and vancomycin for concerns of sepsis. In addition, the patient received an exchange transfusion.

On HD 2, the patient was easily arousable, breathing comfortably with normal pupillary examination. A serum expanded toxicology screen (liquid chromatography/mass spectroscopy) obtained from blood on admission detected codeine, hydromorphone, and morphine. In the patient's urine, each of these were detected as well, with concentrations of $170 \mathrm{ng} / \mathrm{mL}, 551 \mathrm{ng} / \mathrm{mL}$, and $>20,000 \mathrm{ng} / \mathrm{mL}$, respectively. Notable chemistries included a serum creatinine of $3.28 \mathrm{mg} / \mathrm{dL}$ (reference range, $0.57-0.80 \mathrm{mg} / \mathrm{dL}$ ). As the patient became more alert, she reported abdominal pain. A CT of the patient's abdomen and pelvis revealed mild to moderate ascites, bilateral small pleural effusions, bilateral atelectasis/pneumonia, hyperdense borderline enlarged spleen, and mild hepatomegaly. Ultrasonography of her kidneys revealed normal sized kidneys without hydronephrosis, and both main renal arteries and main renal veins were patent. However, given her worsening renal function, she was transferred to a quaternary care, pediatric hospital.

While hospitalized in the quaternary care hospital, her renal function improved. On HD 5, the patient was diagnosed with both acute respiratory distress syndrome and acute chest syndrome requiring endotracheal intubation. A respiratory culture identified human metapneumovirus. On HD 11, she was extubated and complained of visual changes including transient blindness. On HD 12 , she became completely unresponsive, and she was 
reintubated. A head CT was unremarkable. Brain magnetic resonance imaging demonstrated hypoattenuation of posterior occipital and parietal lobes bilaterally consistent with posterior reversible encephalopathy syndrome or an ischemic event associated with sickle cell disease crisis. The patient was administered a nicardipine infusion for blood pressure control. She was extubated on HD 14 with gradual return to normal neurologic function. She was eventually discharged on HD 25. Through the help of social workers, pediatric hematology-oncology, and psychiatry, a plan was developed to have the patient's mother dispense all medications, and the patient was to follow up with specific school-based drug abuse programs as well as her psychiatrist.

\section{Discussion}

The opioid crisis is ubiquitous and far-reaching within the United States, affecting every state, race, gender, and age. ${ }^{3,4}$ Opioid effects highlight the osteopathic principle of the person being a unit of body, mind, and spirit. The relationship between use disorders, the mind, and the physical effects of these chemicals on the body are inseparable. Over the past 2 decades, use and misuse of opioids has escalated. ${ }^{4}$ Carroll et $\mathrm{al}^{5}$ described 83 adult patients who were prescribed chronic opioid therapy and who exhibited

greater levels of clinical pain (particularly non-crisis); central sensitization; and depression and increased diary measures of pain severity, function, and healthcare utilization on crisis and non-crisis diary days, as well as a greater proportion of days in crisis. Overall, the results point out a high symptom burden in sickle cell disease patients on chronic opioid therapy, including those on high-dose chronic opioid therapy, and suggest that nociceptive processing in sickle cell disease patients on chronic opioid therapy differs from those who are not ${ }^{5}$

There has also been much discussion about the appropriate use of opioids in patients with sickle cell disease. ${ }^{6}$

Because of concerns of opioid misuse, the prescribed opioids for the patient presented in this case had been discontinued multiple months prior to her ED presentation. After confirming that no additional prescriptions had been filled via a statewide database search, it remained unclear how the patient had obtained opioids prior to this overdose. Furthermore, it remained unclear whether the patient had administered opioids via her port or via another route. Applying the Naranjo scale, which uses responses to 10 questions to determine the probability of a drug causing an adverse drug reaction, the patient's score of 10 suggested that the opioids were an underlying root cause of her adverse effects; a score of 9 or above indicates a definite adverse drug reaction. ${ }^{7,8}$ Moreover, the drug testing in this patient-given the various opioid metabolic pathways and corresponding literature ${ }^{9}$ - confirmed exposure to either hydromorphone, morphine, codeine, heroin, or even some combination thereof. In multiple conversations with both mother and patient, both were adamant that the patient never used any opioid medications, although both the clinical presentation and drug testing confirmed opioid misuse.

Opioid-related complications in pediatric patients with sickle cell disease have not been previously reported, to the authors' knowledge. One previous case report described an adult male patient with sickle cell disease who died after poisoning from a selfadministered fentanyl patch. The autopsy findings from that report revealed that the patient had died from a combination of acute chest syndrome and respiratory depression. Fentanyl can create acute sickling secondary to chest wall rigidity, along with central respiratory depression. It was thought that the amount of fentanyl detected in the serum sample was enough to cause death by this mechanism. ${ }^{10}$

Exposure to morphine and its active metabolite (morphine-6-glucuronide) after oral administration of slow-release morphine is independently associated with development of acute chest syndrome in patients with sickle cell disease. In a randomized, controlled trial, ${ }^{11} 50$ pediatric patients with sickle cell disease in crisis were randomized to receive either oral or IV morphine. It was postulated that the morphine-induced 
histamine release triggered acute chest syndrome exacerbation. The group receiving oral morphine had a 3 -fold increase in the prevalence of new-onset acute chest syndrome. In contrast, in a separate 6-year casecrossover study, ${ }^{12}$ IV infusions of morphine titrated to adequate pain relief resulted in analgesia without risk of acute chest syndrome.

However, in another study, subtherapeutic as well as supratherapeutic IV morphine were shown to result in abnormal breathing patterns, such as respiratory depression, that predispose patients to acute chest syndrome. ${ }^{13}$ Further, patients with sickle cell disease who have acute kidney injury, renal infarct, or other renal dysfunction may have impaired clearance of morphine metabolites that can also result in increased risk of respiratory depression or acute chest syndrome.

This patient in the current case experienced severe opioid poisoning and had apnea and hypoxemia with multiple ensuing sickle cell disease-related crises as a result. The contribution of naloxone to her presentation remains unclear. While reversal with naloxone was complicated by vomiting in this patient, it is unclear whether this contributed to her complications.

\section{Conclusion}

An opioid overdose in this pediatric patient with sickle cell disease was associated with life-threatening complications. Further study into the effects of opioids, specifically in the pediatric sickle cell disease population, is warranted.

\section{Author Contributions}

Drs Koons and Greenberg provided substantial contributions to conception and design, acquisition of data, or analysis and interpretation of data; Drs Greenberg, Koons, Beauchamp, and Katz drafted the article or revised it critically for important intellectual content; all authors gave final approval of the version of the article to be published; and all authors agree to be accountable for all aspects of the work in ensuring that questions related to the accuracy or integrity of any part of the work are appropriately investigated and resolved.

\section{References}

1. Quinn CT. Sickle cell disease in childhood: from newborn screening through transition to adult medical care. Pediatr Clin North Am. 2013;60(6):1363-1381. doi:10.1016/j.pcl.2013.09.006

2. Buchanan ID, Woodward M, Reed GW. Opioid selection during sickle cell pain crisis and its impact on the development of acute chest syndrome. Pediatr Blood Cancer. 2005;45(5):716-724

3. Pergolizzi JV, LeQuang JA, Berger GK, et al. The basic pharmacology of opioids informs the opioid discourse about misuse and abuse: a review. Pain Ther. 2017;6(1):1-16. doi:10.1002/pbc.20403

4. Manchikanti L, Helm S, Fellows B, et al. Opioid epidemic in the United States. Pain Physician. 2012;15:ES9-38.

5. Carroll CP, Lanzkron S, Haywood C Jr, et al. Chronic opioid therapy and central sensitization in sickle cell disease. Am J Prev Med. 2016;51(1):S69-77. doi:10.1016/j.amepre.2016.02.012

6. Ruta NS, Ballas SK. The opioid drug epidemic and sickle cell disease guilt by association. Pain Med. 2016;17(10):1793-1798. doi:10.1093/ $\mathrm{pm} / \mathrm{pnw} 074$

7. National Institutes of Health. Adverse Drug Reaction Probability Scale (Naranjo) in Drug Induced Liver Injury. LiverTox: Clinical and Research Information on Drug-Induced Liver Injury website. Available at: https:// livertox.nih.gov/Narajo.html. Accessed January 28, 2019.

8. Naranjo CA, Busto $U$, Sellers EM, et al. A method for estimating the probability of adverse drug reactions. Clin Pharmacol Ther. 1981;30:239-245. doi:10.1038/clpt.1981.154.

9. Smith HS. Opioid metabolism. Mayo Clin Proc. 2009;84(7):613-624. doi:10.1016/S0025-6196(11)60750-7

10. Biedrzycki OJ, Bevan D, Lucas S. Fatal overdose due to prescription fentanyl patches in patient with sickle cell/beta-thalassemia and acute chest syndrome: a case report and review of the literature. $A m$ J Forensic Med Pathol. 2009;30(2):188-190.

11. Kopecky EA, Jacobson S, Joshi P, et al. Systemic exposure to morphine and the risk of acute chest syndrome in sickle cell disease. Clin Pharmacol Ther. 2004;75(3):140-146. doi:10.1016/j. clpt.2003.10.007

12. Finkelstein $Y$, Schechter $T$, Garcia-Bournissen $F$, et al. Is morphine exposure associated with acute chest syndrome in children with vaso-occlusive crisis of sickle cell disease? A 6-year case-crossover study. Clin Ther. 2007;29(12):2738-2743. doi:10.1016/j. clinthera.2007.12.016

13. Needleman JP, Benjamin LJ, Sykes JA, et al. Breathing patterns during vaso-occlusive crisis of sickle cell disease. Chest. 2002;122 (1):43-46. doi:10.1378/chest.122.1.43

๑ 2020 American Osteopathic Association 